\title{
A Política de Comércio Exterior dos Governos Obama (2009-2017) à luz do enfoque strangeano: implicações para o regime internacional de comércio ${ }^{1}$
}

\author{
Obama's Foreign Trade Policy (2009 - 2017) \\ in light of Strange's approach: \\ implications for the international trade regime
}

DOI: $10.21530 /$ ci.v13n1.2018.681

Leonardo Diniz Lameiras ${ }^{2}$

\section{Resumo}

O trabalho analisa a política de comércio exterior que foi concebida ao longo dos dois governos de Barack Obama (2009-2017), com o objetivo de revelar suas potenciais implicações para o regime internacional de comércio. Para tanto, faz-se uso do enfoque analítico-metodológico que Susan Strange desenvolve na obra States and Markets, a fim de melhor elucidar os objetivos estratégicos, para além da liberalização comercial, que estão associados à escolha dos mega-acordos regionais como os principais instrumentos da política de comércio exterior do governo democrata. O conceito da autora de poder estrutural é resgatado para entender como a política de comércio exterior serviu ao propósito de fortalecer a posição do país no sistema internacional em quatro domínios específicos: produção, finanças, segurança e conhecimento. De acordo com a hipótese central deste estudo, por intermédio dessa política, os Estados Unidos acentuariam a dinâmica em curso de modificações no arcabouço normativo que rege o sistema multilateral de comércio, submetendo o atual regime internacional que disciplina as trocas comerciais entre os países a significativas transformações.

Palavras-chave: governos Obama; política de comércio exterior; poder estrutural; regime internacional de comércio.

1 Pesquisa financiada pelo CNPq.

2 Mestre em Relações Internacionais pela Universidade de Brasília (IREL/UnB), onde cursou o programa com bolsa de pesquisa do CNPq, e atualmente Doutorando em Relações Internacionais pela Universidade de São Paulo (IRI/USP).

Artigo submetido em 05/06/2017 e aprovado em 18/01/2018. 


\section{Abstract}

The article addresses the foreign trade policy that was conceived throughout the Barack Obama's administration (2009 - 2017), in order to reveal its potential implications for the international trade regime. The analytical and methodological approach devised by Susan Strange in States and markets is thus employed to better elucidate the strategic objectives, beyond trade liberalization, which are associated with the choice of regional mega-agreements as the main tool of the Democratic administration's foreign trade policy. The author's concept of structural power is key to understanding how the foreign trade policy served the purpose of strengthening the country's position in the international system in four specific domains: production, finance, security, and knowledge. According to the central hypothesis of this study, through this policy, the United States would accentuate the ongoing dynamics of changes in the normative framework for governing the multilateral trading system, subjecting the current international regime that disciplines trade between countries to significant transformations.

Keywords: Obama's administration; foreign trade policy; structural power; international trade regime.

\section{Introdução}

A recente decisão do governo de Donald Trump de retirar os EUA da Parceria Transpacífico poderia ofuscar qualquer intento que tenha como motivação o resgate da política de comércio exterior dos governos de Barack Obama enquanto objeto de esquadrinhamento analítico. Afinal, seria razoável supor que poucos se interessariam em debruçar-se sobre um projeto político abortado. No entanto, para além do argumento óbvio que enaltece o valor intrínseco do próprio exame dos fatos pretéritos - empreendimento que dispensa justificativas -, há duas razões de natureza mais pragmática que avalizam o escrutínio do principal legado da administração democrata à inserção internacional dos EUA pela via do comércio: o imperativo de identificar os objetivos estratégicos que levaram o país a engajar-se ativamente nas tratativas de dois mega-acordos de comércio e investimento, com escopo normativo e geográfico inéditos vis-à-vis os demais arranjos comerciais em vigor nos dias hodiernos; e a necessidade de traduzir as possíveis implicações desses instrumentos legais para o atual regime internacional de comércio, caso eles viessem a ser ratificados.

A fim de revelar algumas dessas motivações, que, como será visto, não se restringem tão somente ao fomento da liberalização comercial, convém adotar 
uma chave de leitura que permita analisar com mais acuidade os fenômenos da economia política internacional, realidade social em que se inscrevem as políticas de comércio exterior dos entes estatais. Sendo assim, parte-se do pressuposto de que a aplicação do conceito de poder estrutural, enquanto elemento definidor do enfoque analítico-metodológico concebido por Susan Strange, em States and Markets, vai ao encontro do propósito de descortinar nuances de uma realidade que, nem sempre, são de fácil apercepção, até mesmo para argutos intérpretes das relações internacionais. No caso sob análise, servirá para melhor compreender as escolhas estratégicas que embasaram a formulação da agenda de comércio exterior que foi se delineando ao longo dos governos Obama.

De três seções se vale a estrutura deste artigo. A primeira corresponde ao esforço de síntese do conceito strangeano de poder estrutural, privilegiando as definições que abarcam seus domínios primários de manifestação na economia política internacional. Desde logo, faz-se a ressalva de que não se trata de um trabalho com a finalidade precípua de testar o potencial explicativo da perspectiva analítica da autora, ainda que sua utilidade venha a ser lateralmente posta à prova. Na sequência, à luz desse enfoque, o objeto da análise recairá fundamentalmente sobre os elementos objetivos que influenciaram a definição do conteúdo normativo dos principais instrumentos da política de comércio exterior dos governos Obama, no sentido de tornar menos obscuras as motivações estadunidenses por trás desses projetos. No caso em tela, buscar-se-á demonstrar de que modo esses interesses respondem ao imperativo de fortalecer a posição dos EUA nos quatros domínios primários de manifestação de seu poder estrutural, em consonância com o método de análise proposto pela autora. Por último, a título exploratório, o foco do trabalho se voltará aos desafios que a entrada em vigor dos mega-acordos poderia apresentar ao atual regime internacional de comércio.

\section{O enfoque analítico-metodológico strangeano}

A escolha de resgatar o enfoque analítico-metodológico que Susan Strange apresenta em sua magnum opus States and Markets - fundamentalmente amparado no conceito de poder estrutural - deve-se à sua qualidade de servir como ferramenta de diagnóstico e de interpretação dos fenômenos da realidade internacional contemporânea que nem sempre se revelam de forma aparente, na medida em que, com frequência, seus significados jazem abaixo da superfície dos simples 
relatos que os veículos de comunicação costumam divulgar para o seu público consumidor. Em vez de conceber uma abordagem integralmente teórica, a intenção de Strange foi a de simplesmente dar ao intérprete os ingredientes indispensáveis para fazer a sua própria receita, e nunca o de oferecer-lhe um menu completo, mesmo que esse esteja no formato à la carte (STRANGE, 1994). O entendimento de que, por vezes, as teorias tolhem o alcance da investigação de quem faz uso delas, ao ignorar o potencial explicativo de outras variáveis, encontra guarida na opinião da autora e também serve de motivação para o emprego de seu enfoque analítico-metodológico.

Em sua acepção elementar, o poder estrutural é definido pela autora como sendo aquele capaz de determinar e transformar as estruturas da ordem econômica e política mundial, submetendo Estados, instituições políticas, grupos econômicos e integrantes da sociedade civil global a um modus operandi que tanto pode criar oportunidades quanto impor desafios às suas escolhas políticas. Trata-se, acima de tudo, do poder de definir a agenda de discussão ou de criar as regras e os costumes que definem os regimes internacionais destinados a governar as relações econômicas internacionais (STRANGE, 1994). Para os atores que dele podem fazer uso, portanto, significa possuir a prerrogativa de modificar arcabouços normativos e institucionais dentro dos quais outros atores interagem e se relacionam (STRANGE, 1994). Nesse aspecto, é marcante a diferença em relação ao conceito realista de poder relacional, que se restringe ao entendimento mais convencional da capacidade que determinado ator dispõe de influenciar o comportamento alheio por meio da ameaça ou do emprego de recursos tangíveis, a fim de lograr resultados anteriormente idealizados.

Ao entendimento de que as ações dos Estados podem provocar mudanças estruturais que influenciarão o comportamento e as escolhas futuras dos atores internacionais, Strange também acrescenta um componente não intencional, ou mesmo "inconsciente"3, que atenua o teor de voluntarismo do comportamento estatal na avaliação dos eventos que lhe sucedem. Desse modo, a autora também chama atenção para os efeitos difusos que o uso do poder estrutural acarreta na economia política internacional, especialmente em um contexto marcado pela crescente interdependência econômica com a ativa participação de novos atores econômicos e políticos (GUZZINI, 1993).

3 Segundo uma concepção antropomorfizada das unidades políticas estatais. 
O modo pelo qual esse tipo de poder se expressa na economia política internacional pode ser ilustrado, como faz a autora, pela figura geométrica de uma pirâmide (Figura 1) com quatro faces triangulares, cada qual correspondendo a uma estrutura primária de poder, que, juntas, conformam o próprio poder estrutural. Cada face está em contato com as outras três, de modo a representar a mútua influência que uma exerce na outra e a interação constante entre as quatro estruturas superiores do poder estrutural; a saber: a estrutura de produção, de segurança, de finanças (ou crédito) e de conhecimento (STRANGE, 1994).

Figura 1. A pirâmide de Strange e as quatro faces do poder estrutural

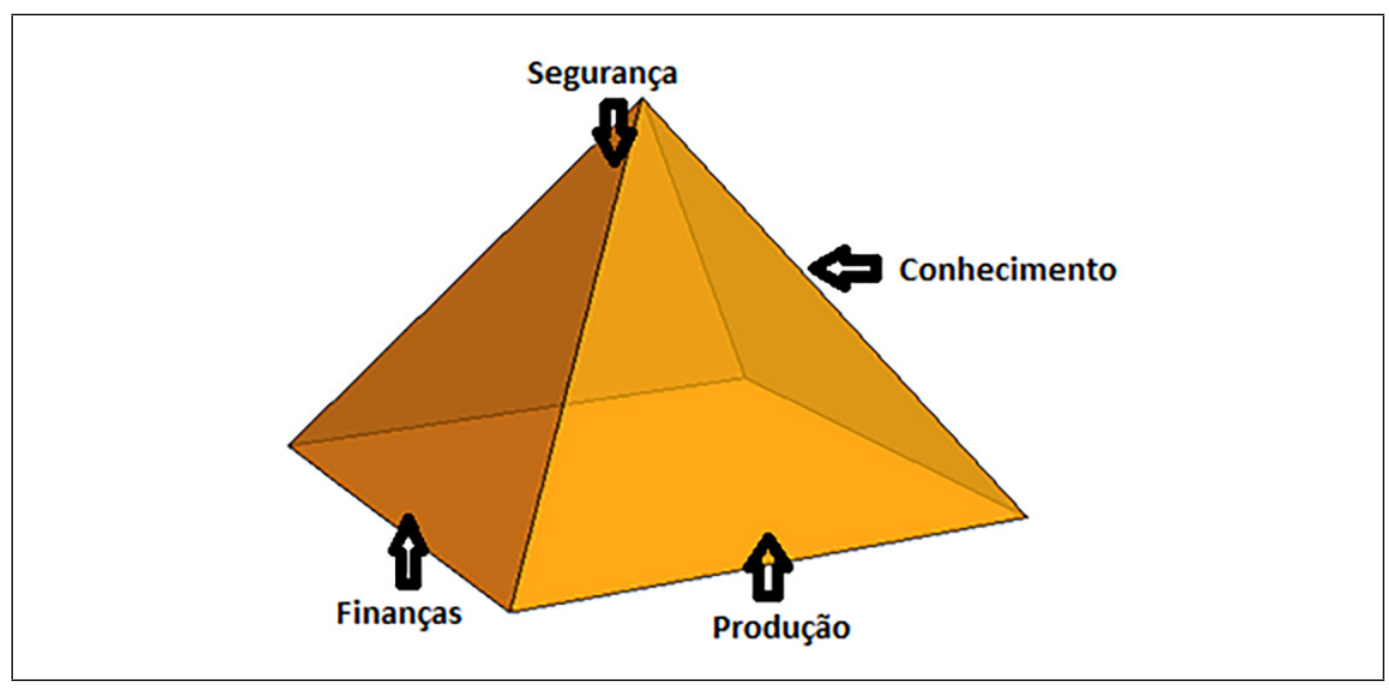

Fonte: Adaptado de Strange (1994, p. 27).

Em comum a todas elas, aparece a faculdade, por parte daquele que faz uso do poder estrutural, de modificar os cálculos de custo-benefício e o leque de escolhas estratégicas dos demais atores do sistema internacional, sem que haja a necessidade de recorrer a ameaças ou de empregar meios coercitivos para torná-la efetiva. Essa dinâmica implica um método mais sutil e menos explícito de manejo do poder, que se distingue das formas mais tradicionais e triviais de seu exercício quando levadas a cabo pelas unidades políticas estatais (STRANGE, 1994).

A estrutura primária de segurança expressa poder, nos marcos da economia política, sempre que houver a provisão de segurança de um ou mais atores a outros. Nessa relação, o grupo ou agente provedor de segurança adquire certa reserva de poder que lhe permite influenciar, ou mesmo determinar, o leque de escolhas dos beneficiários. Com efeito, ao exercer esse poder, os provedores de segurança podem extrair vantagens especiais dentro de outros domínios estruturais, a exemplo de privilégios comerciais ligados à venda e à compra de produtos e de 
direitos especiais associados à apropriação e à distribuição de riquezas (STRANGE, 1994). “Desse modo, a estrutura de segurança, inevitavelmente, tem impacto sobre quem leva o que na economia” (STRANGE, 1994, p. 45, tradução livre ${ }^{4}$ ).

A estrutura primária de produção “pode ser definida como sendo a soma de todos os arranjos que determinam o que, por quem, para quem, por meio de quais métodos e sobre quais termos se produz" (STRANGE, 1994, p. 64, tradução livre ${ }^{5}$ ). Trata-se, ao mesmo tempo, daquilo que é produzido em determinado espaço econômico, ou seja, do produto destinado à venda e ao consumo, e do modo como o trabalho e os demais fatores de produção são organizados para que a produção seja realizada com êxito. Em última instância, é essa estrutura de poder a responsável por criar riqueza, e mudanças nela geralmente promovem novas configurações de poder na ordem política e social (STRANGE, 1994).

Não menos importante para o exercício do poder estrutural no âmbito da economia política internacional é a estrutura primária das finanças. Define-se como sendo tanto o poder de criar crédito, isto é, de facilitar ou negar a outros agentes a prerrogativa de despender no presente e quitar a dívida no futuro, bem como o poder de conceber o sistema financeiro internacional onde serão acordados os meios que determinarão os valores relativos das diferentes moedas nacionais. No primeiro caso, governos e bancos são os agentes que exercem a autoridade de realizar políticas creditícias, já no segundo, a agência advém das políticas governamentais e do próprio mercado, ambas fundamentais para a precificação das diferentes moedas no mercado cambial (STRANGE, 1994).

Em contraste com as demais fontes, o poder estrutural que deriva da estrutura primária do conhecimento assume formas de expressão menos explícitas e transparentes na economia política internacional. Traduz-se como sendo o poder de determinar "qual conhecimento é descoberto, como é armazenado, por que meio, por quem e sob quais condições ele é transmitido a outrem” (STRANGE, 1994, p. 121, tradução livre ${ }^{6}$. Sua natureza intangível e não quantificável faz dessa estrutura um objeto quase incognoscível, mesmo entre aqueles que reconhecem sua importância nas relações internacionais.

4 No original: "Thus the security structure inevitably has an impact on the who-gets-what of the economy".

5 No original: "can be defined as the sum of all the arrangements determing what is produced, by whom and for whom, by what method and on what terms"

6 No original: "what knowledge is discovered, how it is stored, and who comunicates it by what means to whom and on what terms". 
Além dessas quatro estruturas primárias de poder, como complemento e subordinadas a elas, Strange (1994) adiciona a seu método de análise outras quatro estruturas que ela classifica como secundárias. São elas: os sistemas de transporte, o comércio, a energia e a estrutura de bem-estar. Como denominador comum, todas apresentam influência e peso significativos entre as forças políticas e econômicas que definem as regras de convívio e competição a que os atores se submetem uma vez concebidas. Outrossim, tal como ocorre dentro dos domínios primários da estrutura de poder, prevalece uma interação constante entre as forças econômicas do mercado e o poder político dos Estados, e, no âmbito de cada uma, as escolhas também são realizadas com base nos valores e nas preferencias dos atores. A classificação de secundárias revela o grau de dependência e submissão delas em relação às estruturas primárias.

\section{Os principais instrumentos da política de comércio exterior da era Obama}

Apresentados como modelos para os acordos regionais de comércio do século XXI, tanto a Parceria Transpacífico (TPP) quanto a Parceria Transatlântica de Comércio e Investimento (T-TIP) foram concebidas como meios de expressão do poder estrutural dos EUA na ordem internacional contemporânea. Em sentido amplo, isso se deve ao fato de ambos os instrumentos legais se prestarem ao objetivo último de definir a agenda de discussão e de criar as regras e os costumes que moldariam o atual regime internacional de comércio, o que vai muito além da simples pretensão de estabelecer uma área de livre-comércio ou uma união aduaneira entre as partes contratantes. Stricto sensu, esse reconhecimento se justifica pelo conteúdo legal que os dois tratados fariam incidir sobre seus destinatários, ao preverem regras e normas que, ao mesmo tempo, aprofundariam e expandiriam o arcabouço normativo do sistema multilateral de comércio a que hoje se submetem os signatários e futuros aderentes dos mega-acordos.

Em perspectiva histórica, os dois projetos foram aos poucos ganhando relevância no desenho das diretrizes da política de comércio exterior dos EUA, sobretudo a partir do segundo governo Obama, quando a administração logrou reunir as condições necessárias para um engajamento mais assertivo nas tratativas comerciais. Ao longo de quase todo o primeiro governo, ao contrário, o que prevalecera havia sido uma postura introvertida e ambivalente no que se refere 
às iniciativas de liberalização comercial. A crise financeira que acomete o país de maneira avassaladora no início do mandato de Obama e a agenda do Partido Democrata, crítica dos acordos de livre-comércio negociados na era "Bush filho" e reivindicatória de uma proteção ${ }^{7}$ mais robusta dos postos de trabalho ameaçados pela concorrência externa, impuseram-se como os principais entraves para ensaios mais alvissareiros que permitissem uma correção de rumo.

Para o abandono desse imobilismo estadunidense algumas variáveis de natureza sistêmica e doméstica foram determinantes, entre as quais concorreram a recuperação econômica do país, a menor incidência de projetos de lei ${ }^{8}$ que acentuassem a clivagem partidária entre republicanos e democratas em matéria de política comercial e a renitente paralisia da Rodada Doha de negociações multilaterais no âmbito da Organização Mundial de Comércio (OMC). Sendo assim, diante de uma conjuntura mais permissiva aos seus desígnios, a administração democrata pôde envolver-se com mais afinco nas negociações em torno do TPP e do T-TIP a partir do início do segundo mandato de Obama (2013-2017), mesmo que a gênese de suas investidas anteceda a reeleição de Obama.

A origem da Parceria Transpacífico deita raízes em um acordo plurilateral de livre-comércio assinado em 2005 por quatro países - Chile, Brunei, Nova Zelândia e Singapura -, a chamada Parceria Econômica e Estratégica Transpacífico (ou simplesmente Acordo P-4), que tinha como principal meta servir de modelo para uma expansão futura com o ingresso de países dos dois lados do Pacífico, de modo a abarcar não apenas todos os membros do fórum Cooperação Econômica Ásia-Pacífico (APEC, na sigla em inglês), mas também parceiros dos demais continentes (LEWIS, 2011). A denominação de Parceria Transpacífico só veio a ser consubstanciada em março de 2008, quando os EUA tornaram explícitas suas intenções de negociar sua adesão, coincidindo com o início das discussões entre os países signatários do P-4 sobre novos temas, como serviços financeiros e investimentos (BARFIELD; LEVY, 2009). A mudança de governo nos EUA fez com que o calendário dessas primeiras rodadas de negociação, das quais também participariam Austrália, Peru e Vietnã, ficasse suspenso até a definição de uma agenda mais concreta sobre os fundamentos e as diretrizes que norteariam a política de comércio exterior do país (LEWIS, 2011).

7 Objetivo que seria logrado por meio das renovações da chamada Trade Adjustment Assistance.

8 A exemplo dos embates entre democratas e republicanos em torno da aprovação dos pacotes econômicos de natureza anticíclica (que teve no American Recovery and Reivestment Act de 2009 a sua maior expressão), da reforma do sistema público de saúde (mais conhecido como Obamacare) e das medidas que visavam à descarbonização da matriz energética do país. 
Embora estivessem ausentes da composição originária do TPP, a partir do momento em que tomam assento nas negociações, não tardaria para que os EUA se tornassem o maior fiador do projeto. O ativo engajamento do país não apenas resultou em modificações consideráveis no conteúdo do tratado pela inclusão de novas disciplinas que fossem ao encontro de seus interesses, mas também na expansão do número de sócios, como nos casos das aproximações que sua diplomacia realizou junto aos governos mexicano e canadense para que aderissem ao processo negociador em 2012. Esforço repetido com o governo japonês, que acabou resultando no ingresso do país asiático no ano seguinte.

Após sua assinatura, no dia 4 de fevereiro de 2016, por 12 países - EUA, Japão, Austrália, Brunei, Canadá, Chile, Peru, Malásia, México, Nova Zelândia, Singapura e Vietnã -, o acordo da Parceria Transpacífico havia entrado em fase de aprovação nos parlamentos nacionais - pelo menos onde havia previsão legal - quando sobreveio a decisão unilateral do governo Trump de retirar os EUA por meio de uma ordem executiva. Em conjunto, as 12 nações constituem quase $40 \%$ do PIB mundial e quase um terço do comércio global. (U.S. TRADE REPRESENTATIVE, 2015). Aferir o impacto econômico do acordo para o bloco não é trivial, mas um estudo estima que " $\$ 77$ bilhões por ano seriam adicionados à renda real dos EUA até 2025” (PETRI, 2015, s/p, tradução livre9).

Sem apresentar o mesmo desfecho, as negociações em torno do T-TIP, que haviam sido efetivamente lançadas em $2013^{10}$, ainda permanecem inconclusas e sem um encaminhamento definido por parte da nova administração republicana. Caso a Comissão Europeia - órgão executivo da União Europeia que negocia em nome dos 28 países membros do bloco - e os EUA cheguem a um consenso sobre o texto final do tratado, o T-TIP aprofundará uma parceria que atualmente constitui a mais relevante do mundo em termos de volume de comércio e investimento. De fato, as cifras são portentosas. Juntos, o país e o bloco correspondem a quase metade do PIB mundial e a um terço de todo o comércio global. Para se ter noção da magnitude do nível de integração que existe entre ambos os parceiros mesmo sem a vigência do acordo, em 2011, os fluxos comerciais de bens e serviços totalizaram

9 No original: “\$77 billion per year would be added to US real incomes by 2025".

10 O primeiro anúncio oficial foi realizado ainda no início do segundo governo Obama, no tradicional discurso do presidente sobre o Estado da União (State of the Union Address) diante da elite política estadunidense, embora a origem do projeto remonte à formação do Grupo de Trabalho de Alto Nível sobre Emprego e Crescimento, em 2011, quando os EUA e a União Europeia estabeleceram conversas formais para encontrar uma saída para a crise econômica. 
aproximadamente €702.6 bilhões, e os de investimento estrangeiro direto (IED) $€ 2.394$ trilhões, o que faz com que cada um seja para o outro o principal destino de exportação e de investimento (COMISSÃO EUROPEIA, 2013).

À semelhança das conversas sigilosas que caracterizaram as negociações sobre o acordo da Parceria Transpacífico, cujo conteúdo foi mantido em segredo até a conclusão das tratativas, a nova parceria em construção entre EUA e UE também vem sendo alvo de críticas devido à pouca transparência com que os encarregados das negociações conduzem seus trabalhos. A despeito desse segredo em relação ao texto do instrumento jurídico, o discurso oficial estadunidense qualifica o T-TIP como um acordo que terá um escopo normativo amplo, no qual, além da abertura de mercado para investimentos e da desgravação tarifária para o comércio de bens e serviços, prevê-se a inclusão de cláusulas que disciplinam as relações dos países em matérias que extrapolam o conteúdo legal dos tradicionais acordos de livre-comércio, tais como direitos ambientais e trabalhistas, comércio digital, propriedade intelectual, barreiras não tarifárias e regulatórias, compras governamentais, entre outras (U.S. TRADE REPRESENTATIVE, 2015). Na hipótese de um acordo com essa amplitude vir a ser celebrado, as projeções dos ganhos econômicos são significativas:

Em um cenário ambicioso, o modelo prevê crescimento de 0,48\% do PIB para a União Europeia, comparado à referência do ano-base. Nos EUA, aumentos do PIB atingiriam 0,39\% . Para a UE, esses ganhos estimados corresponderiam a um incremento de 86 bilhões de euros na renda nacional. Para os EUA, o montante comparável seria de 65 bilhões de euros. (COMISSÃO EUROPEIA, 2013, p. 37, tradução livre ${ }^{11}$ )

\section{Os mega-acordos e seu conteúdo estratégico à luz da ótica strangeana}

Como antes asseverado, outros fins estratégicos não circunscritos aos ganhos estritamente comerciais fundamentaram o projeto de inserção internacional estadunidense pela via do comércio. No âmbito da estrutura primária de produção, ou seja, naquela em que se define "o que”, "por quem” e "para quem” se produz, tanto o TPP quanto o T-TIP funcionam como organizadores da estrutura produtiva

11 No original: "Under the ambitious scenario, the model predicts GDP increases for the EU of $0.48 \%$ compared to the baseline option. In the US, GDP increases would amount to $0.39 \%$. For the EU, these estimated gains amount to an increase of national income by €86bn. For the US, the comparable amount would be €65bn". 
mundial, ao fazerem dos EUA um polo de atração de investimentos, amparado nas vantagens comparativas de seu mercado nacional, a exemplo de mão de obra altamente qualificada, acesso facilitado ao crédito e segurança jurídica.

Nesse embate por um reposicionamento estratégico na estrutura produtiva mundial, as normas trabalhistas e ambientais previstas nos referidos acordos reduziriam as vantagens competitivas dos países onde os custos econômicos com a exploração dos recursos naturais e com a mão de obra fossem baixos. As empresas norte-americanas que a esses mercados acorriam para aproveitar tais vantagens, com a entrada em vigor do TPP, por exemplo, receberiam incentivos para instalarem suas unidades produtivas nos EUA. O próprio discurso oficial do governo Obama não deixa margem a dúvidas quanto à imbricação entre sua política de comércio exterior e a estrutura primária de produção:

Por intermédio de nossa agenda comercial, nós estamos procurando colocar os EUA no centro de uma zona de comércio cobrindo quase dois terços da economia global. Isso ajudará a fazer dos EUA a plataforma mundial de produção de escolha, aumentando as exportações norte-americanas e atraindo mais empregadores que querem investir nos EUA, contratar trabalhadores norte-americanos e vender bens e serviços norte-americanos para o mundo. (U.S. TRADE REPRESENTATIVE, 2015, p. 7, tradução livre'12)

Estreitas conexões entre as escolhas estratégicas da política comercial e a estrutura primária das finanças, outra dimensão do poder estrutural, também podem ser deduzidas do conteúdo dos mega-acordos. Em negociação entre os possíveis signatários do T-TIP, e já contemplada no acordo do TPP, figura um capítulo específico sobre serviços financeiros. Sem querer esgotar o conteúdo do que está previsto no TPP nessa matéria, chama atenção determinados compromissos específicos, como a exigência de que as partes permitam a livre oferta de serviços de pagamento eletrônico, favorecendo as firmas norte-americanas, desde há muito consolidadas no mercado de serviços de crédito eletrônico e de pagamento em débito; a proibição de interferências no trânsito de informações para o processamento de dados que seja necessário ao funcionamento das atividades financeiras; a permissão para a adoção de expedientes emergenciais no contexto de uma eventual crise financeira; e o estabelecimento de sistema específico

12 No original: "Through our trade agenda, we are seeking to put the United States at the center of a trade zone covering nearly two-thirds of the global economy. That will help make America the world's production platform of choice, increasing U.S. exports and attracting more employers that want to invest in the United States, hire American workers, and sell American goods and services to the world". 
de solução de controvérsias quando envolver medidas financeiras regulatórias (TRANS-PACIFIC PARTNERSHIP AGREEMENT, Capítulo 11, 2015).

Ofertantes dos mais sofisticados e competitivos serviços financeiros do mundo, cujas exportações, segundo dados do USTR ${ }^{13}$ (2016), contribuem para um acréscimo de superávit no balanço de pagamentos da ordem de $\$ 68$ bilhões, as firmas estadunidenses só terão a ganhar com a entrada em vigor dos megaacordos regionais, dadas suas imensas vantagens comparativas nesse setor econômico. Apenas na região da Ásia-Pacífico, as oportunidades que as aguardam estão longe de ser desprezíveis. No ano de 2013, os países signatários do TPP consumiram $\$ 16$ bilhões em serviços financeiros advindos dos EUA (U.S. TRADE REPRESENTATIVE, 2016). Constituindo o maior canteiro de obras do mundo, o acesso ao crédito por parte do setor público e privado torna-se imprescindível na consolidação dos investimentos nos países situados nos dois lados do Pacífico.

O controle sobre o que pode ser descoberto e a forma como se armazena e se distribui o conhecimento constitui mais uma faceta do poder estrutural. No âmbito dessa estrutura primária, os instrumentos da política estadunidense de comércio exterior exercem uma função altamente estratégica. Em grande medida, isso se deve aos chamados direitos de propriedade intelectual que os EUA patrocinam por meio de previsões legais inseridas nos acordos de livre-comércio que o país vem firmando com outras nações desde a década de 1980 (HERREROS, 2011). Com o TPP e o T-TIP, o objetivo é expandir ainda mais essa rede de proteção, tanto em relação ao número de parceiros comerciais que a ela ficaria sujeito quanto no que diz respeito ao seu alcance temporal.

Em um mundo em que o desenvolvimento socioeconômico está umbilicalmente ligado à capacidade de produzir conhecimento e desenvolver novas tecnologias, prazos mais dilatados de proteção contra o risco de determinado conhecimento privado cair em domínio público dificilmente se traduzem em vantagem aos países cujo estado da arte do sistema produtivo e dos centros de pesquisa ainda estão distantes da fronteira tecnológica. A extensão do monopólio privado para além de um limite razoável, subtraindo de outros países a faculdade de acessar o conhecimento com o propósito de empregá-lo em políticas públicas que se reverteriam em ganhos sociais, perpetua as vantagens comparativas dos EUA na econômica mundial.

13 O chamado Office of the United States Trade Representative é a agência do Poder Executivo encarregada de formular as diretrizes da política de comércio exterior e de negociar acordos comerciais. 
Além de estarem implicados em considerações estratégicas no domínio das estruturas primárias da produção, das finanças e do conhecimento, os mega-acordos também visam a satisfazer os interesses estadunidenses em questões atinentes à segurança do país em um mundo em redefinição. No segundo governo Obama, quando as negociações do TPP e do T-TIP eram encaminhadas pelos negociadores norte-americanos em 2014, o encarregado da chefia do USTR, Michael Froman, em artigo publicado na Foreign Affairs, fez a seguinte declaração:

Assim como concluir o TPP ressaltaria o compromisso de Washington com o desenvolvimento e a estabilidade da Ásia durante um tempo de fluxo, finalizar a Parceria Transatlântica de Comércio e Investimento (T-TIP) enviaria um sinal inequívoco ao mundo sobre a força do laço europeu-estadunidense um lembrete oportuno, já que a crise na Ucrânia tem provocado um profundo desconforto em todo o continente. (FROMAN, 2014, s/p, tradução livre'14)

Na concepção do representante norte-americano, os dois pilares da política de comércio exterior do governo Obama também abarcam cálculos de natureza político-militar para duas regiões que apresentam dinâmicas complexas de equilíbrio de poder. No caso do velho continente, a menção específica à Ucrânia revela as tensões ainda vivas no Leste Europeu entre a Rússia, país que reluta em aceitar qualquer perda de influência na região que sua diplomacia denomina de o "estrangeiro próximo", e a OTAN, a aliança de defesa militar que, com o fim da Guerra Fria, fez da expansão em direção ao Leste, a partir da adesão de novos membros ao bloco, um de seus principais objetivos estratégicos. Nessa perspectiva, o T-TIP serviria como um reforço à aliança atlântica, ao aproximar ainda mais os países europeus dos EUA. Acercamento esse que ganha relevo no contexto atual em que a guerra na Síria surge como um potencial catalizador para o agravamento de antigas rivalidades no Oriente Médio.

No xadrez geopolítico da Ásia-Pacífico, o "tempo de fluxo" a que se referiu Froman expressa as incertezas com o ativo engajamento chinês na região, que em certos momentos leva ao descrédito o discurso oficial do Partido Comunista sobre a "ascensão pacífica" do país no sistema internacional. Contenciosos lindeiros no Tibete com a Índia e disputas no mar do Leste com o Japão e no mar do Sul da

14 No original: "just as completing the TPP would underscore Washington's commitment to development and stability in Asia during a time of flux, finalizing the Transatlantic Trade and Investment Partnership (T-TIP) would send an unmistakable signal to the world about the strength of the U.S.-European bond - a timely reminder, as the crisis in Ukraine has triggered deep unease across the continent". 
China com Filipinas, Vietnã, Malásia, Brunei e Taiwan são alguns dos desafios que se apresentam aos EUA e a seus aliados históricos, como Japão, Taiwan, Coreia do Sul e Austrália; todos esses, abrigados pelo guarda-chuva das forças militares norte-americanas e ciosos da conveniência de poder contar com os EUA para frear as supostas pretensões hegemônicas chinesas em seu entorno regional.

Afora isso, na opinião de muitos especialistas (HERREROS, 2011; LEWIS, 2011; BARFIELD; LEVY, 2009), o TPP teria o propósito de servir como contraponto a um projeto de regionalismo que fosse orquestrado sob a batuta da China e que excluísse os EUA da região onde se encontram albergadas as economias mais dinâmicas do mundo. Tendo isso em vista, interessava ao governo Obama largar na dianteira da corrida para escrever as "regras do jogo" que irão disciplinar as relações econômicas naquele espaço regional no futuro próximo. Para tanto, seria necessário que o TPP se impusesse como a proposta de regionalismo mais adequada para a Ásia-Pacífico, superando a atratividade exercida por dois projetos - a ele concorrentes, mas complementares entre si - que coibiriam os EUA de ditarem os rumos da dinâmica integracionista de acordo exclusivamente com seus valores e interesses.

O primeiro desses projetos leva o nome de Área de Livre-Comércio da Ásia-Pacífico (Free Trade Area of the Asia-Pacific - FTAAP): uma iniciativa da APEC que vem sendo negociada há aproximadamente uma década, mas que ganhou ânimo renovado em 2014 com o endosso chinês e dos demais membros do agrupamento para a elaboração de um “mapa do caminho”, com vistas a viabilizar a conclusão do acordo no curto ou médio prazo. A segunda proposta de regionalismo, que não apenas vem recebendo o explícito apoio chinês, como também de outras potências asiáticas, e da qual os EUA estão excluídos, consiste na chamada Parceria Econômica Regional Abrangente (Regional Comprehensive Economic Partnership - RCEP). Lançada em 2012, a iniciativa reavivou o projeto nipônico que havia recebido a alcunha de "ASEAN + 6"15 (HERREROS, 2011).

Ao apresentar-se como opção aos projetos que contemplam um regionalismo estritamente intra-asiático, o TPP alinha-se à orientação mais geral da política externa do governo Obama de fazer da Ásia o "pivô” para a inserção internacional

15 Mecanismo institucional criado em 2006 e que previa a meta de estabelecer uma área de livre comércio entre os dez membros daquela organização do Sudeste asiático e outros seis países - Japão, China, Índia, Coreia do Sul, Austrália e Nova Zelândia. Vale lembrar que a própria ASEAN possui acordos de livre-comércio com cada um desses países que não são membros plenos do bloco, conquanto ainda não exista uma área de livre-comércio entre as seis pujantes economias. 
dos EUA. No âmago desse reposicionamento estratégico, presente em uma série de declarações oficiais que vinham sendo anunciadas desde os últimos meses de 2011, há o reconhecimento pelo governo de que "a prosperidade futura e a segurança dos EUA estão entrelaçadas com a região do Pacífico e da Ásia Oriental” (BUREAU OF PUBLIC AFFAIRS, 2013). Disso resulta o emprego de um conjunto de ações que, junto com a Parceria Transpacífico, dão sustentação ao rebalancing norte-americano. Entre elas, duas se destacam: o fortalecimento da presença militar dos EUA na região - a despeito do anunciado corte de gastos na área de defesa pelo governo Obama - levado a cabo com o envio de mais tropas à Austrália, com a implementação de novos programas de cooperação militar com as Filipinas e com o deslocamento de forças navais à Singapura; e o ingresso dos EUA, em 2011, na Cúpula do Leste da Ásia (East Asia Summit), um dos principais fóruns asiáticos para deliberações sobre questões de segurança (MANYIN et al., 2012).

Não obstante os riscos inerentes a qualquer exercício especulativo que tente antecipar acontecimentos futuros, indícios sugerem que essas diretrizes gerais de política externa não serão preservadas no governo Trump. Em conformidade com a sua diplomacia do America First, ao decidir pela saída dos EUA da Parceria Transpacífico e enaltecer o protecionismo comercial, o novo mandatário opta deliberadamente por não fazer uso do poder estrutural norte-americano, deixando o caminho livre para que a China tenha mais controle sobre as iniciativas voltadas à regulamentação do comércio regional e à construção de plataformas institucionais com lastro nos interesses e valores sínicos.

\section{As implicações dos mega-acordos para o regime internacional de comércio}

Objetivamente, uma vez feitas as considerações que enquadram a política de comércio exterior dos EUA na perspectiva do poder estrutural strangeano, uma das perguntas que suscita investigação é: seriam o TPP e o T-TIP instrumentos normativos ratificadores de uma tendência que vem submetendo o regime internacional de comércio a significativas transformações?

Convém antes esclarecer que inexiste uma definição irretocável acerca do conceito de "regime internacional" na literatura especializada sobre o tema. Ademais, fugiria do escopo deste trabalho tentar qualificar o atual "estado da arte” da produção acadêmica cujo propósito tem sido o de identificar a existência 
de regimes internacionais com base em uma definição unívoca, portanto, que fosse amplamente aceita pelas correntes teóricas, independente dos elementos epistemológicos, ou mesmo ontológicos, que as embasam e as diferenciam umas das outras. Por ora, é suficiente dizer que a definição de Stephen Krasner ainda se mostra útil para os estudos que versam sobre regimes internacionais, na medida em que permite identificar os processos de transformação a que eles estão suscetíveis, malgrado as críticas ${ }^{16}$ referentes à falta de precisão dos significados que alguns de seus elementos conceituais comportam. De acordo com o entendimento do autor, regimes internacionais:

podem ser definidos como conjuntos de princípios, normas, regras e procedimentos de tomada de decisões, implícitos ou explícitos, em torno dos quais convergem as expectativas dos atores em determinada área das relações internacionais. Os princípios são crenças em fatos, causas e questões morais. As normas são padrões de comportamento definidos em termos de direitos e obrigações. As regras são prescrições ou proscrições específicas para a ação. Os procedimentos para tomada de decisões são práticas predominantes para fazer e implementar escolhas coletivas (KRASNER, 1982, p. 186, tradução livre'17).

Dessa definição Krasner conclui que haveria mudança no regime sempre que ocorressem modificações nas regras e nos procedimentos de tomada de decisão, considerando que os princípios e as normas que o governam permaneçam inalteradas (KRASNER, 1982, p. 187). Por outro lado, mudanças de regime seriam observadas quando os princípios e as normas que o regem fossem abandonados, abrindo espaço tanto para o surgimento de um novo regime quanto para o seu desaparecimento em determinada área temática das relações internacionais (KRASNER, 1982, p. 188).

No curso do processo de regulamentação do comércio internacional que debuta com a entrada em vigor do GATT $47^{18}$ e se estende até o presente, verifica-se uma tendência que começou a manifestar-se desde o início da década de 1990 e que ganha novo ímpeto quando os primeiros impasses na Rodada

\footnotetext{
16 Em geral, chamam a atenção para a falta de clareza entre o que diferencia regras (prescrições ou proscrições especificas para a ação) de normas (padrões de comportamento definidos em termos de direitos e obrigações).

17 No original: "can be defined as sets of implicit or explicit principles, norms, rules, and decision-making procedures around which actors' expectations converge in a given area of international relations. Principles are beliefs of fact, causation, and rectitude. Norms are standards of behavior defined in terms of rights and obligations. Rules are specific prescriptions or proscriptions for action. Decision-making procedures are prevailing practices for making and implementing collective choice".
}

18 O Acordo Geral de Tarifas e Comércio de 1947. 
Doha vieram à tona na década seguinte (Gráfico 1). Trata-se da proeminência assumida pelos mecanismos ad hoc em relação às negociações multilaterais da OMC na dinâmica regulamentadora, realidade que vem sendo caracterizada por especialistas no assunto como o fenômeno do spaghetti bowl (Figura 2). Em função desse processo, o regime internacional de comércio foi se sujeitando, aos poucos, a uma tendência de enfraquecimento, sintomática do grau de incompatibilidade entre o comportamento dos atores e o próprio regime. Com efeito, ao conferir prioridade às vias bilaterais e regionais em detrimento da $\mathrm{OMC}$ como centro inovador e uniformizador das normas que regulamentam o comércio internacional, o caminho escolhido por determinados atores estatais vem prejudicando a construção de um arcabouço normativo constituído fundamentalmente por normas e regras que sejam coerentes entre si e que tenham como destinatário a maioria dos partícipes do comércio internacional.

\section{Gráfico 1. Todos os acordos regionais de comércio notificados ao GATT/OMC} entre 1949 e 2015

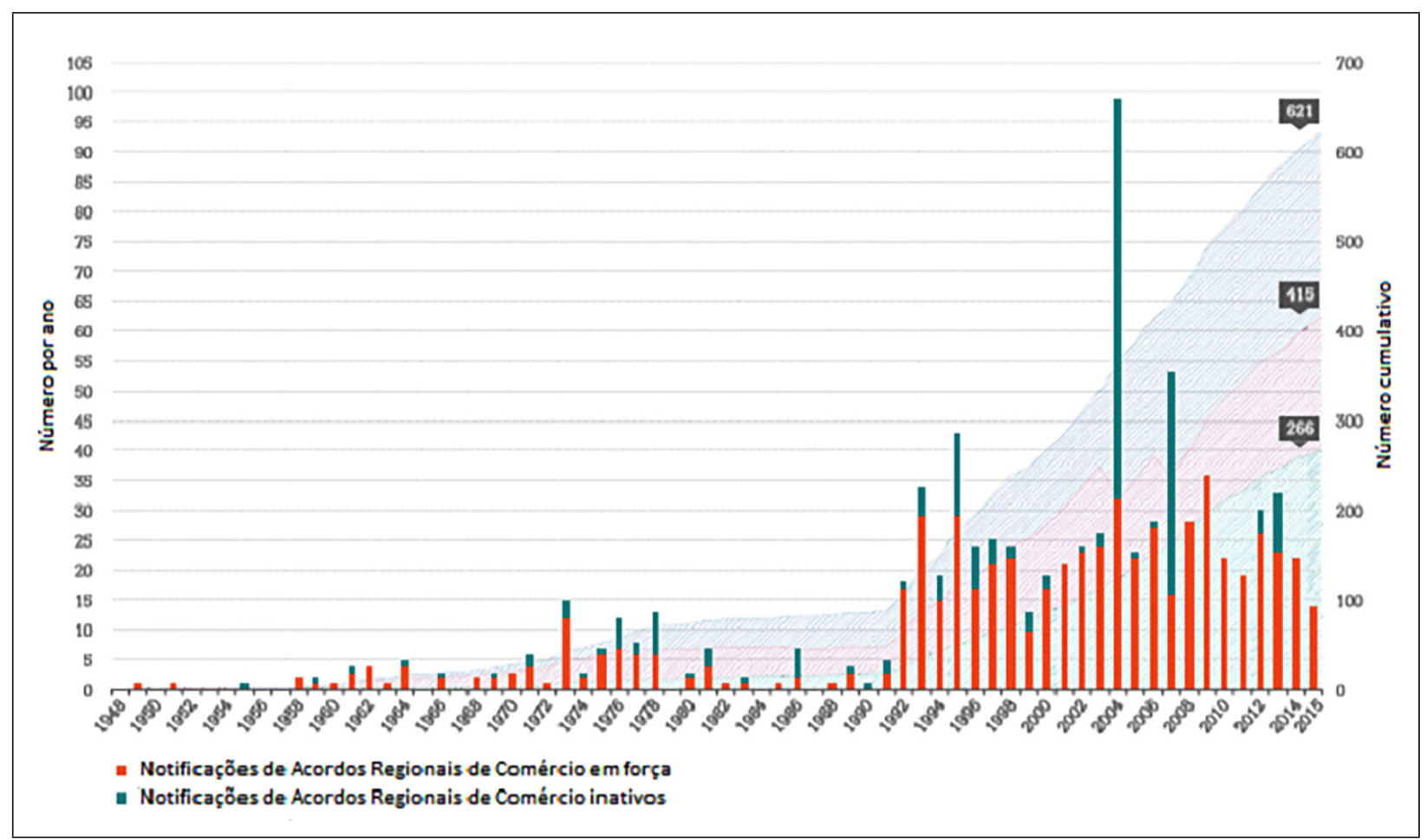

Fonte: Adaptado de Secretariado da OMC (2017).

Dessa dinâmica desordenada, dois sistemas de governança do comércio passariam a coexistir lado a lado: um ainda ditado pela pauta das negociações multilaterais da OMC, com ênfase nos tradicionais temas de sua agenda, como acesso a mercado e subsídios agrícolas, e que recebe o apoio, em grande medida, 
dos países emergentes; e outro associado à dinâmica de internacionalização das cadeias globais, demandante de novas disciplinas regulamentadoras, e que vem sendo forjado pelas nações inseridas nesse circuito fragmentado de produção por intermédio de acordos regionais de comércio, tratados bilaterais de investimento e reformas unilaterais (BALDWIN, 2012).

Figura 2. O spaghetti bowl dos acordos de livre-comércio no continente americano ${ }^{19}$

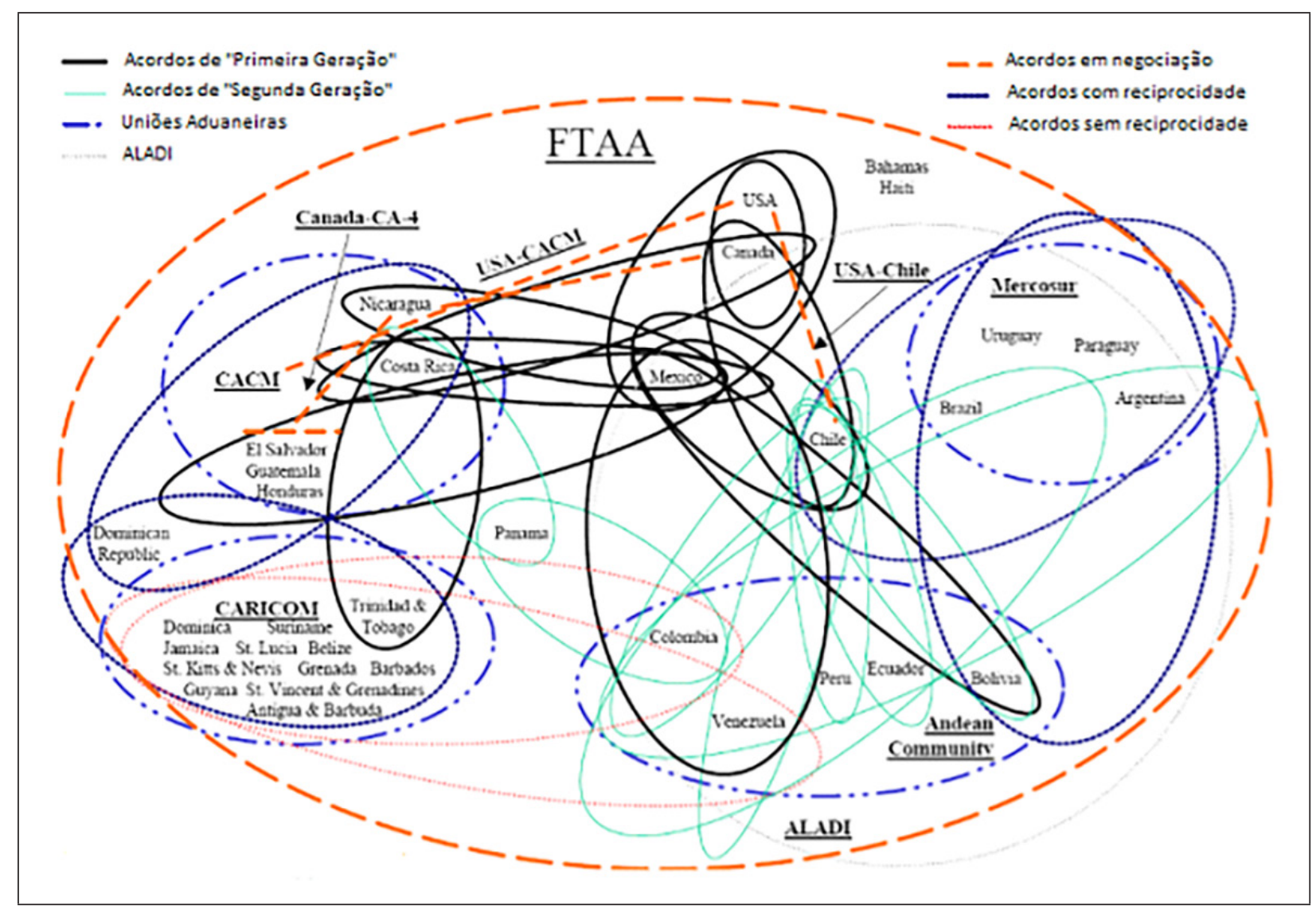

Fonte: Adaptado de Gallagher (2011, p. 9).

Nesse diapasão, o que se observa é um processo de atomização da dinâmica de produção de normas e regras que apresentam conteúdos heterogêneos entre si e vocacionadas a produzir efeitos jurídicos apenas para um número limitado de atores (efeitos inter partes), à diferença dos efeitos erga omnes que emanam dos acordos multilaterais da OMC. Afora isso, como fator agravante para a

19 Entre os acordos de livre-comércio (FTAA) ilustrados pela figura constam: a Associação Latino-Americana de Integração (ALADI), o Mercado Comum do Sul (MERCOSUR), a Comunidade Andina (ANDEAN COMMUNITY), a Comunidade Caribenha (CARICOM), o Mercado Comum da América Central (CACM), o acordo entre os EUA e a CACM (USA-CACM) e o acordo entre o Canadá e os países da América Central (CANADA-CA 4). 
corrosão funcional do regime, os novos acordos comerciais ${ }^{20}$ deixaram de ser apenas emuladores do arcabouço normativo da OMC para tornarem-se fontes inovadoras em virtude da adoção de espécies normativas do gênero "OMC-Plus"21 e "OMC-Extra"22 (HORN; MAVROIDIS; SAPIR; 2009).

No ápice desse processo, situam-se os principais instrumentos da política comercial dos governos Obama. Além de os mega-acordos aprofundarem a regulamentação de temas que extrapolam o escopo normativo do sistema multilateral de comércio, os mesmos instrumentos também logram reunir um número bastante expressivo de países que, conjuntamente, representam uma proporção significativa dos fluxos globais de comércio - mais da metade em termos de valores gerados com as vendas de bens e serviços.

De volta à discussão dos impactos plausíveis sobre o regime internacional de comércio, a compatibilização entre os fatos analisados e os elementos conceituais até aqui discorridos apenas autoriza afirmar que a política de comércio exterior dos governos Obama - mais precisamente por intermédio dos mega-acordos (TPP e T-TIP) - buscou colocar-se como um novo paradigma entre os demais fatores causais que fazem entrever mudanças no regime, mas não permite concluir que suas implicações também promoveriam a mudança do regime internacional de comércio.

Estudos que analisam o texto do TPP - seja colocando-o em perspectiva comparada com alguns dos acordos constitutivos da OMC (BRAGA, 2016), seja situando-o em relação a outros acordos preferenciais de comércio e investimento (ALSCHNER; SKOUGAREVSKIY, 2015; CHITTOORAN, 2015; CHITTOORAN, 2016), a exemplo do que apresenta o Quadro $1^{23}$ - fornecem uma sólida base empírica que atesta o objetivo estadunidense de reescrever as regras do comércio internacional, tanto por meio de prescrições específicas enquadradas na tipologia "OMC-Plus" e "OMC-Extra” (primeira condição) quanto pela modificação dos procedimentos de tomada de decisão (segunda condição), valendo-se, para isso, de um mecanismo

20 Os chamados acordos comerciais de terceira geração, que têm como característica mais saliente um conteúdo normativo com considerável grau de transversalidade com outros regimes internacionais.

21 Aquelas regras que tratam dos mesmos temas regulamentados pelos acordos multilaterais da OMC, mas que aprofundam seu conteúdo normativo, a exemplo dos direitos de propriedade intelectual.

22 Compromissos que extrapolam o mandato da organização, na medida em que buscam disciplinar temas que ainda não são objeto de regulamentação pelo direito da OMC, como as cláusulas trabalhistas e ambientais.

23 No quadro apresentado por Chittooran (2016), os acordos são classificados em três categorias - Bronze, Prata e Ouro. Preferiu-se apenas numerá-las (1, 2 e 3) com a finalidade de eliminar o viés de predileção por um ou outro instrumento normativo. 
próprio de solução de controvérsias ${ }^{24}$, dotado de normas de natureza procedimental, o qual funcionaria à margem do sistema consagrado pela OMC.

Quadro 1. As categorias dos acordos comerciais assinados pelos EUA e seus respectivos compromissos "OMC-Extra" em matéria de direitos trabalhistas e ambientais

\begin{tabular}{|c|c|c|c|}
\hline $\begin{array}{l}\text { COMPROMISSOS } \\
\text { "OMC-EXTRA" }\end{array}$ & $\begin{array}{l}\text { CATEGORIA } 1 \\
\text { Singapura (2004) } \\
\text { Chile (2004) } \\
\text { Austrália (2005) } \\
\text { Marrocos (2006) } \\
\text { CAFTA-DR (06-09) } \\
\text { Bahrein (2006) } \\
\text { Omã (2009) }\end{array}$ & $\begin{array}{c}\text { CATEGORIA } 2 \\
\text { Peru (2009) } \\
\text { Colômbia (2009) } \\
\text { Coreia do Sul (2012) } \\
\text { Panamá (2012) }\end{array}$ & CATEGORIA 3 \\
\hline $\begin{array}{l}\text { Compromisso de cumprir a } \\
\text { própria legislação doméstica } \\
\text { sobre direitos trabalhistas }\end{array}$ & SIM & SIM & SIM \\
\hline $\begin{array}{c}\text { Compromisso de adotar e } \\
\text { observar os direitos trabalhistas } \\
\text { consagrados pelas convenções } \\
\text { da OIT }\end{array}$ & NÃO & SIM & SIM \\
\hline $\begin{array}{l}\text { Compromisso de desencorajar a } \\
\text { importação de bens produzidos } \\
\text { por meio de trabalho forçado }\end{array}$ & NÃO & NÃO & SIM \\
\hline $\begin{array}{c}\text { Proibição de renúncia ou } \\
\text { derrogação das leis ambientais } \\
\text { para encorajar o comércio e o } \\
\text { investimento }\end{array}$ & SIM & SIM & SIM \\
\hline $\begin{array}{l}\text { Proibição de subsídios à pesca } \\
\text { ilegal e predatória }\end{array}$ & NÃO & SIM & SIM \\
\hline $\begin{array}{l}\text { Implementação da Convenção } \\
\text { sobre o Comércio Internacional } \\
\text { de Espécies da Fauna e da Flora } \\
\text { Selvagens Ameaçadas } \\
\text { de Extinção }\end{array}$ & NÃO & NÃO & SIM \\
\hline
\end{tabular}

Fonte: Adaptado de Chittooran $(2015,2016)$.

24 A exemplo do mecanismo de solução de controvérsias previsto no Capítulo IX do TPP, onde estão regulamentadas as medidas de investimento relacionadas ao comércio, que autoriza o investidor privado a acionar diretamente o referido mecanismo sem que, para isso, haja a necessidade de recorrer à autoridade pública de seu Estado para representá-lo junto à autoridade arbitral, mesmo quando a acusação seja dirigida contra uma entidade estatal. 
Quanto à mudança de regime, mesmo que se atribua a regras e normas significados intercambiáveis, a análise do conteúdo do TPP não permite concluir que o mega-acordo possui o potencial de provocar o abandono do arcabouço normativo que hoje rege o regime internacional de comércio. Tampouco a entrada em vigor do instrumento legal provocaria a obsolescência da dimensão principiológica do sistema multilateral de comércio, ao ponto de anunciar o completo esfacelamento do atual regime ou sua substituição por um novo. A despeito do processo de marginalização que acomete a OMC nos dias de hoje, em função das forças centrífugas (mormente os acordos preferenciais de comércio da terceira geração e os mega-acordos da era Obama) atuantes no sistema multilateral de comércio, a dinâmica regulamentadora que afeta o intercâmbio comercial permanece assentada sobre os princípios ${ }^{25}$ basilares que foram consagrados pelos acordos multilaterais da OMC, com o fito de promover a liberalização comercial e evitar o recrudescimento do protecionismo em nível global.

\section{Conclusões}

Ao buscarem definir a agenda de discussão e criar as regras e os costumes que redefiniriam o regime internacional de comércio, impondo a outros atores novas escolhas e desafios em suas relações econômicas, os mega-acordos constituíram os meios, por excelência, com os quais o governo Obama decidiu operacionalizar o poder estrutural norte-americano, a fim de preservar as vantagens competitivas dos EUA na ordem econômica mundial. Sob a ótica strangeana, o TPP e o T-TIP devem ser entendidos como instrumentos legais que se prestariam a satisfazer outras finalidades estratégicas para além dos ganhos estritamente comerciais, no sentido de também salvaguardarem os interesses norte-americanos nas quatro estruturas primárias que conferem expressão objetiva ao poder estrutural do país.

No domínio da estrutura primária de produção, os inéditos acordos regionais funcionariam como reorganizadores da estrutura produtiva mundial, na medida em

25 Segundo renomados doutrinadores, a exemplo de Van den Bossche (2007) e Amaral Júnior (2008), trata-se dos mesmos princípios que inspiraram a celebração do GATT 47, acrescidos de outros que, com aqueles, passaram a integrar os acordos constitutivos da OMC. São eles: o princípio da consolidação dos compromissos; o princípio da não discriminação (a cláusula de nação mais favorecida e o princípio do tratamento nacional); o princípio da transparência; o princípio que consagra as medidas excepcionais (as chamadas válvulas de escape); e o princípio do tratamento especial e diferenciado aos países em desenvolvimento e de menor desenvolvimento relativo. 
que reafirmariam a posição dos EUA nas cadeias globais de produção como polo de atração de investimentos e, não apenas, como exportadores de IED ao resto do mundo. Por intermédio da uniformização de normas e regras, esse nivelamento das condições de competição beneficiaria as firmas estadunidenses, que passariam a contar com um ambiente jurídico mais seguro para a realização de investimentos de médio e longo prazos nos países signatários daqueles tratados.

No que diz respeito à estrutura de finanças, setor econômico em que os EUA despontam com amplas vantagens comparativas por serem ofertantes dos mais sofisticados serviços financeiros em escala global, assinalou-se o fato de o TPP e o T-TIP preverem um capítulo específico sobre a matéria, com compromissos que visam a promover o desmonte das legislações domésticas que, por exemplo, proibissem as firmas estrangeiras de prestarem determinados serviços ou impusessem restrições à transferência de informações e dados necessários a certas operações financeiras. Entre outros, essa desregulamentação responde ao imperativo estadunidense de controlar parte do acesso ao crédito na Ásia-Pacífico: região que atualmente apresenta as mais altas taxas de investimento do mundo.

Em relação ao controle do que pode ser descoberto e ao modo segundo o qual o conhecimento é distribuído, as normas sobre direitos de propriedade intelectual constantes nos acordos adensariam o nível de proteção em vigência no atual sistema multilateral de comércio. Isso iria ao encontro dos interesses dos EUA de assegurarem aos seus nacionais - indivíduos e empresas - garantias monopolísticas estendidas nos mercados estrangeiros, mesmo que, para tanto, por vezes, implicassem custos elevados para os cidadãos dos países onde o acesso a determinado conhecimento é imprescindível para a melhoria de sua condição socioeconômica, a exemplo do acesso a medicamentos para o tratamento de patologias endêmicas.

Questões concernentes à estrutura primária de segurança complementaram a análise sobre os desdobramentos sistêmicos que adviriam com a entrada em vigor dos mega-acordos. Aspectos de natureza geopolítica reforçam seu conteúdo estratégico, que apenas pela leitura dos textos legais ficaria difícil antever. No caso em tela, o reforço da aliança atlântica entre os EUA e os países europeus, contra uma Rússia refratária a qualquer incursão em seu “estrangeiro próximo”, e o projeto de regionalismo para a Ásia, que se apresenta como um contrapeso à liderança chinesa na região, encontram guarida, respectivamente, nas motivações estratégicas de segurança e defesa do T-TIP e do TPP.

Tendo como parâmetro referencial a definição de Krasner sobre regimes internacionais, bem como a análise do autor a propósito das possíveis transformações 
a que eles estão sujeitos, foi possível situar os dois projetos estadunidenses na vanguarda de uma tendência mais ampla que vem provocando mudanças no atual regime internacional de comércio. Um movimento geral que tem na sobreposição de subsistemas normativos e, por conseguinte, no esvaziamento funcional da OMC, seu traço mais saliente. Dentro desse contexto, interessava ao governo democrata continuar a escrever as "regras do jogo" que disciplinariam o comércio internacional, mas sem dilapidar o próprio regime capaz de conferir uma base axiológica comum a todo o seu agregado normativo, de modo a salvaguardar a proeminência dos EUA em uma ordem internacional em redefinição.

\section{Referências}

AMARAL JÚNIOR, Alberto do. Introdução ao direito internacional público. São Paulo: Atlas, 2008.

ALSCHNER, Wolfgang; SKOUGAREVSKIY, Dmitriy. The new gold standard? Empirically situating the TPP in the investment treaty universe. Graduate Institute of International and Development Studies: Center for Trade and Economic Integration, Genebra, 20 nov. 2015. Disponível em: < http://repository.graduateinstitute.ch/record/293805/files/ CTEI\%202015-8\%20Alschner_Skougarevskiy_TPP. pdf > . Acesso em: 05 mai. 2016. BALDWIN, Richard. WTO 2.0: global governance of supply-chain trade. Center for Economic Policy Research. Policy Insight, n. 64, dez. 2012. Disponível em: http://www.cepr.org/sites/default/files/policy_insights/PolicyInsight64.pdf > . Acesso em: 12 mar. 2015.

BARFIELD, Claude; LEVY, Philip I. Tales of the South Pacific: President Obama and the Transpacific Partnership. American Enterprise Institute for Public Policy Research, n. 2, dez. 2009. Disponível em: < https://www.aei.org/wp-content/uploads/2011/10/09IEO-Dec-g.pdf > . Acesso em: 11 ago. 2016.

BOSSCHE, Peter Van den. The law and policy of the World Trade Organization. Cambridge: Cambridge University Press, 2007.

BRAGA, Carlos A. Primo. Innovation, trade and IPRs: implications for trade negotiations. Working Paper, East-West Center Workshop on Mega-Regionalism. New Challenges for Trade and Innovation, mar, 2016. Disponível em: < https://papers.ssrn.com/ sol3/papers.cfm?abstract_id =2745500\#\# > . Acesso em: 13 out. 2016.

CHITTOORAN, Jay. TPP in brief: labor standards. Third Way Fresh Thinking. Economy Memo, 18 nov. 2015. Disponível em: < http://www.thirdway.org/memo/tpp-in-brieflabor-standards > . Acesso em: 20 out. 2016. 
CHITTOORAN, Jay. TPP in brief: environmental standards. Third Way Fresh Thinking. Economy Memo, 15 abri. 2016. Disponível em: < http://www.thirdway.org/memo/ tpp-in-brief-environmental-standards > . Acesso em: 21 out. 2016.

COMISSÃO EUROPEIA. Impact assessment report on the future of EU-US trade relations. Commission Staff Working Document, Strasbourg, 2013. Disponível em: < http://trade. ec.europa.eu/doclib/docs/2013/march/tradoc_150759.pdf > . Acesso em: 28 ago. 2016. FROMAN, Michael B. The Strategic Logic of Trade: New Rules of the Road for the Global Market. Foreign Affairs, nov-dez. 2014.

GALLAGHER, Kevin. Trading away stability and growth: United States trade agreements in Latin America. Political Economy Research Institute, n. 266, set. 2011. Disponível em: < https://www.peri.umass.edu/media/k2/attachments/WP266.pdf > . Acesso em: 10 ago. 2016.

GUZZINI, Stefano. Structural power: the limits of neorealist power analysis. International Organization, v. 47, n. 3, 1993, p. 443-478. Disponível em: < http://cadmus. eui.eu/bitstream/handle/1814/23701/Guzzini_IO_1993_CUP. pdf? sequence $=2$ \&is Allowed $=\mathrm{y}>$. Acesso em: 22 dez. 2015.

HERREROS, Sebastián. The Trans-pacific Strategic Economic Partnership Agreement: a Latin American perspective. United Nations/ECLAC: Division of International Trade and Integration, mar. 2011. Disponível em: < http://repositorio.cepal.org/bitstream/ handle/11362/4332/S1100160_en.pdf? sequence $=1$ \&isAllowed $=y>$. Acesso em: 03 jul. 2016.

HORN, H.; MAVROIDIS, P. C.; SAPIR, A. Beyond the WTO? An anatomy of EU and US preferential trade agreements. CEPR Discussion Paper (n. DP7317), jun. 2009. Disponível em: < http://papers.ssrn.com/sol3/papers.cfm?abstract_id $=1433913>$. Acesso em: 07 out. 2016.

KRASNER, Stephen. Structural causes and regimes consequences: regimes as intervening variables. International Organization, v. 36, n. 2, spring, 1982, p. 185-205. Disponível em: < https://www.jstor.org/stable/2706520?seq=1\#page_scan_tab_contents > . Acesso em: 11 jun. 2015.

STRANGE, Susan. States and markets (2. ed.). London: Pinter Publishers, 1994.

LEWIS, Meredith Kolsky. The Trans-Pacific Partnership: New Paradigm or Wolf in Sheep's Clothing? Boston College International and Comparative Law Review, v. 34, n. 01, 1 jan. 2011. Disponível em: < http://lawdigitalcommons.bc.edu/cgi/viewcontent. cgi article $=1264 \&$ context $=$ iclr $>$. Acesso em: 19 set. 2016 .

MANYIN, Mark E.; DAGGETT, Stephen; DOLVEN, Ben; LAWRENCE, Susan V.; MARTIN, Michael F.; O'ROURKE, Ronald; VAUGHN, Bruce. Pivot to the Pacific? The Obama Administration's “Rebalancing” Toward Asia. Congressional Research Service, 28 mar. 2012. Disponível em: < https://fas.org/sgp/crs/natsec/R42448.pdf > . Acesso em: 03 abr. 2016. 
WORLD TRADE ORGANIZATION SECRETARIAT. Regional trade agreements: facts and figures. Disponível em: < https://www.wto.org/english/tratop_e/region_e/regfac_e.htm > . Acesso em: 12 dez. 2016.

PETRI, PETER A. What economic models tell us about the TPP. Peterson Institute for International Economics, 18 fev. 2015. Disponível em: < https://piie.com/blogs/ trade-investment-policy-watch/what-economic-models-tell-us-about-tpp? $\mathrm{p}=106>$. Acesso em: 10 ago. 2016.

U.S. TRADE REPRESENTATIVE. Federal Register. U.S.-EU High Level Working Group on Jobs and Growth. Disponível em: < https://www.regulations.gov/document? D = U STR-2012-0001-0001 > . Acesso em: 20 jul. 2016.

U.S. TRADE REPRESENTATIVE. The President's 2009 Trade Policy Agenda. Disponível em: < https://ustr.gov/sites/default/files/uploads/reports/2009/asset_upload_ file810_15401.pdf > . Acesso em: 13 jun. 2016.

U.S. TRADE REPRESENTATIVE. The President's 2010 Trade Policy Agenda. Disponível em: < https://ustr.gov/sites/default/files/uploads/gsp/speeches/reports/2010/Annual \% 20Report/Chapter \% 20I \% 20President’s \% 20Trade \% 20Policy \% 20Agenda.pdf > . Acesso em: 18 jun. 2016.

U.S. TRADE REPRESENTATIVE. The President's 2011 Trade Policy Agenda. Disponível em: < https://ustr.gov/sites/default/files/uploads/gsp/speeches/reports/IP/ACTA/ about \% 20us/press \% 20office/reportspublications/2011/Chapter \% 20I. \% 20The \% 20 Presidents \% 202011 \%20Trade\%20Policy\%20Agenda.pdf > . Acesso em: 21 jun. 2016.

U.S. TRADE REPRESENTATIVE. The President's 2012 Trade Policy Agenda. Disponível em: < https://ustr.gov/sites/default/files/FULL \%20REPORT \% 20\%20PRINTED \% 20 VERSION.pdf > . Acesso em: 25 jun. 2016.

U.S. TRADE REPRESENTATIVE. The President's 2013 Trade Policy Agenda. Disponível em: < https://ustr.gov/sites/default/files/Chapter \% 20I\%20\%20The\%20President's \% 20 Trade \%20Policy \%20Agenda.pdf > . Acesso em: 30 jun. 2016.

U.S. TRADE REPRESENTATIVE. The President's 2014 Trade Policy Agenda. Disponível em: < https://ustr.gov/sites/default/files/Chapter \% 20I\%20The \% 20Presidents \% 20 Trade \%20Policy\%20Agenda.pdf > . Acesso em: 05 jul. 2016.

U.S. TRADE REPRESENTATIVE. The President's 2015 Trade Policy Agenda. Disponível em: < https://ustr.gov/sites/default/files/President \% 27s \%20Trade \% 20Agenda \% 20 for \%20Print \%20FINAL.pdf > . Acesso em: 15 jul. 2016.

U.S. TRADE REPRESENTATIVE. The President's 2016 Trade Policy Agenda. Disponível em: < https://ustr.gov/sites/default/files/2016-Trade-Policy-Agenda.pdf > . Acesso em: 02 jul. 2016. 
TRANS-PACIFIC PARTNERSHIP AGREEMENT. TPP Full Text. Disponível em: < https://ustr. gov/trade-agreements/free-trade-agreements/trans-pacific-partnership/tpp-full-text > . Acesso em: 20 mar. 2016.

U.S. DEPARTMENT OF STATES. The East-Asia Rebalance: Expanding U.S. Engagement. Bureau of Public Affairs. Disponível em: < http://www.state.gov/documents/ organization/218988.pdf $>$. Acesso em: 01 set. 2016. 